\title{
A SHIPPING LINE STOWAGE PLANNING PROCEDURE IN THE PRESENCE OF HAZARDOUS CONTAINERS
}

\author{
Daniela Ambrosino, Anna Sciomachen \\ Department of Economics and Business studies, University of Genoa \\ Via Vivaldi 5, 16126 Genova, Italy \\ ambrosin@economia.unige.it, sciomach@economia.unige.it
}

\begin{abstract}
This work addresses the stowage planning problem for containerships, known as the Master Bay Plan problem (MBPP), in the presence of hazardous containers. A novel procedure, based on the principles included in the International Maritime Dangerous Goods (IMDG) Code for stowing containers in liner services is presented. Further, shipping alliances are considered. Our aim is to assist the shipping line coordinator (SLC) to optimize the available space assigned to each alliance member. This is possible thanks to the proposed procedure that finds stowage solutions for ships with different structures, capacity and available sections for hazardous containers, and for companies having different stowage strategies. Our procedure can be implemented in a tool able to verify the stowage constraints and the segregation rules in case of hazardous cargo. Two simple real-life multi-port stowage plans involving hazardous containers are presented and analyzed to illustrate the proposed procedure.
\end{abstract}

Keywords: Stowage plans; hazardous containers; liner shipping; segregation table; International Maritime Dangerous Goods; shipping alliance.

\section{Introduction}

Nowadays, about $90 \%$ of non-bulk cargo worldwide is carried into containers. Since the 1960s, the twenty/forty-foot equivalent unit (TEU/FEU) are the standards by which container volume is measured. This refers to a container with external dimensions of $8^{\prime}$ (feet) in height, 8' in width and 20'/40' in length. There are different sizes of container vessels too; their maximum size has increased spectacularly since the introduction of the container and the containerization. The larger containerships of the past were up to 5,000 TEUs, the smallest of recent years, whereas the most common range today is between 10,000 and 18,000 TEUs. At the time of writing, containerships of 22,000 TEUs are being built.

The main characteristic of containerships is that they are Lo-Lo (Lift on - Lift off) ships, i.e. loading/unloading containers from the top by shore-based equipment. With the use of quay cranes, 
also known as Ship-to-Shore cranes or STS, the loading and unloading process is extremely fast, as cargohandling operations strongly impact both the efficiency of the terminal and that of the shipping line (and its choices) (see, e.g. Carlo et al, 2013; Imai et al, 2013; Rashidi and Tsang, 2013 and Pacino et al, 2011, among others).

The stowage planning of a containership is carried out, usually on a daily basis, by dedicated employees of the shipping companies and of the container terminals. The terminal decides where containers have to be loaded aboard ship, according to the instructions received by the shipping company. Thus, the shipping line coordinator (SLC) and the terminal planner (TP) solve the same problem, albeit at a different level of detail, interacting during the process. The main differences of the stowage planning problem, faced by these two decision makers, are highlighted in Ambrosino et al (2017). Imai et al (2006) present a unified approach for addressing the route planning problem, from both the liner and the terminal manager point of view. We should note that, from a decision point of view, the stowage planning problem, often denoted as MBPP, is a NP hard optimization problem (Avriel et al, 2000; Tierney et al, 2014). For this reason, quite a large number of heuristics have been recently proposed in literature (see, e.g. Wilson and Roach, 2000; Ambrosino et al, 2009; Ding and Chou, 2015 among others).

In the preparation of a stowage plan, the SLC or the TP have to consider different variables, such as the size of the containers, their weight and destination. The SLC must also take into account the contents of the containers, particularly regarding hazardous goods. Dangerous goods increase the risk of explosions, emission of noxious gases and other damages to the ship, the crew and the containers (see Table 1 for a list of classes of dangerous goods).

Recent works concerning the MBPP in the presence of hazardous goods include Ambrosino and Sciomachen (2015) and Parreno et al. (2016). Ambrosino and Sciomachen (2015) approached the problem by following the relation between MBPP and the 3Dimensional - Bin Packing Problem. In particular, they showed how the segregation rules for dangerous goods necessitate changes to the loading pattern. Parreno et al (2016) include hazardous containers in the slot planning problem, considering only rules concerning stowage limitations related to the stacks (stack segregation; see below).

It should be noted that, during the last century, sea transport of dangerous goods was not so important as to gain the attention of international organizations, urging them to adopt a universally applicable framework. Today, the situation is different and dangerous goods are a new subject matter of law, in terms of safety and pollution prevention. Regulation, standardization of transportation, loading, unloading and stowage of dangerous goods is today essential.

Many are the international regulations regarding dangerous goods. Chapter VII of the Safety Of Life At Sea (SOLAS) convention is entirely focused on the carriage of dangerous goods. In this Chapter of the SOLAS, the International Maritime Dangerous Goods (IMDG) Code is made mandatory. In essence, the IMDG Code provides the fundamentals, including operating advices -for specific substances and objects- on packing, marking and labelling, handling, stowage and segregation. Hazardous goods regulations are also included in the Prevention of Maritime Pollution from Ships Convention (MARPOL 73/78); which is the main international convention covering prevention of 
pollution of the marine environment by ships from operational or accidental causes (IMO, 1978). MARPOL was adopted in 1973 and includes Annex III, which contains general guidelines on packing, marking, labelling, stowing, limitations, exceptions and notifications of dangerous goods.

Furthermore, the IMGD Code, together with its amendment of 2014, recalls also the International Convention for Safe Containers (CSC), also developed by IMO (1972). CSC has two goals: a) to maintain a high level of safety in the transport and handling of containers by providing generally acceptable procedures and strength requirements; b) to facilitate the international transport of containers by providing uniform international safety regulations, equally applicable to all modes of surface transport.

This work presents a procedure to address the requirements concerning the stowage of dangerous containers together with other containers aboard a containership. With respect to the previous works on stowage problems with hazardous containers, we focus on a procedure useful to the SLC. Moreover, we give a detailed description of the stowage planning process, including, for the first time in literature, the problem of loading containers in bays allocated to different members of global shipping alliances.

The stowage planning process is presented in more detail in Section 2, while the problem under investigation is described in Section 3. In Section 4, the segregation rules, as defined in the IMDG Code, are illustrated. In Section 5, we present our procedure, aimed at supporting the SLC in defining stowage plans involving hazardous containers. Two simple case studies, aimed at exemplifying the proposed procedure, are given and analyzed in Section 6. Finally, conclusions and outlines of future research are given.

\section{The stowage planning process}

Correct stowage planning is important for both carrier and terminal, the latter aiming to offer highquality services to calling containerships, through the efficient utilization of resources such as berths, cranes, yard spaces and machines. In so doing, the terminal aims to reduce operating costs, thus gaining efficiency and comparative advantage over its competitors. Shipping companies choose those terminals able to grant them reliable services and quick turnaround times (a good survey of optimization techniques in marine terminals can be found in Stahlbock and Voss (2008)).

Generally, the design of a stowage plan consists of two consecutive and iterative phases (Steenken $e t$ al, 2004, Ambrosino et al, 2017). The first phase pertains to the SLC: this has a complete view of the containers to be loaded/unloaded at each port, and of the structure of the vessel. The SLC receives the origin-destination information and decides whether to accept a transport demand or not. Further, the SLC defines a stowage plan for each port in the route and updates it whenever a new transport demand is received and accepted. Such a plan is quite general, giving instructions to the TP on where the containers (grouped according to their destination, size, type and weight) should be stowed in the ship. The SLC must determine the exact location on board only for the hazardous containers. (The recent research on MP-MBPP (multi-port stowage planning), from the SLC perspective, includes, among others, Wilson et al (2001), Pacino et al (2011), Ambrosino et al (2015)). The second phase involves 
the TP. A terminal plan is carried out at each port of the route, taking into account only the containers to be loaded at that terminal. The TP must determine the exact location of each to-be-loaded container (except for hazardous containers, whose location is established beforehand), following the pre-stowage instructions received from the SLC. The TP establishes the sequence of loading operations for the handling equipment, such as quay cranes and horizontal transport means (Monaco et al, 2014). At each terminal, the TP defines a detailed stowage plan for the containers to load and communicates it to the SLC, who updates this continuously.

Stowage planning becomes especially challenging, but also interesting from an academic point of view, if one considers the needs of alliances, and the way their carrier-members arrange their capacity requirements through slot-chartering on each other's ships. By means of alliance agreements, a vessel's capacity is shared among alliance members. In the context of such an agreement, the parties are: the "owner", that is the shipping line whose ship the alliance decided to allocate in the route; and the "slot charterers", partners (shipping lines) interested in a portion of the ship capacity in that route. Given the number of slot charters on each ship operating in the route, the ship is divided into sections, allocated to the various slot charterers, as decided by the alliance. The owner of the ship in question is contractually responsible for stowage planning, loading, unloading and lashing of containers on board the ship. Each section, corresponding to sets of bays, is assigned to one alliance member so that each of them effectively charters the number of slots assigned to him. An example of a partition of a ship among three alliance members is shown in Figure 1.

Insert Figure 1 here

Then, on the basis of the number, type and weight limits stipulated by the contract, the booking department of each member reserves slots to its customers. Before the booking closing time, all slot requests are aggregated in the stowage plan of the SLC, who has the role of checking whether to accept the demands. The SLC assigns containers (grouped together according to their slot charterer) to the slots chartered by the member. Then, the SLC associates to those slots the containers grouped according to their destination, taking into account the available quay cranes at the destination ports. In this phase, the SLC checks whether the number of TEUs to carry aboard by each partner exceed the assigned capacity. Simultaneously, he also checks if the number of TEUs to be loaded onboard does not exceed the capacity of the ship. The incompatibilities between pairs of (dangerous) containers according to their class of hazard, and the rules of the IMDG Code are verified too. In doing this, the SLC communicates continuously with the booking department. Then, before the arrival of the ship at a scheduled port, he sends the feasible general plan to the TP. This plan indicates, for each member, and for each destination, in which part of the ship to load containers, while specific slots are assigned to hazardous containers. On that basis, the TP decides which slot will be assigned to what container, which is his main task.

\section{Problem under investigation}

In this paper we focus on the role of the SLC in stowage planning. As we have already explained above, the SLC receives a certain transport demand, by an alliance member, for a given ship, and he must decide whether it is possible to accept the demand and, if so, how to stow the containers onboard, 
given the characteristics of the ship, the sequence of ports of call, and the cargo already onboard or booked. The containers are characterized by their size, type, weight and destination port. As far as the type is considered, standard cargo, reefers, open top, and hazardous containers can be loaded. With regard to size, only 20 and 40-foot containers are included in the present analysis.

Containers are loaded in the slots made available to the requesting carrier. To better explain the problem in hand, assume we have a transport demand by partner A1, for non-hazardous containers, from port 2 to port 4 of the route of the ship in question. The SLC must decide on where to load the containers among the available locations in bays $22,26,30,54,58,62$, which are those assigned to A1 (see Figure 1). In Figure 2, the available locations of bay 22 are sketched. The SLC can consider a whole bay (Figure 2a), or hold and deck locations of a bay (Figure 2b), or hold and deck hatch locations of a bay (Figure 2c) respectively, hatch deck S1-S2-S3 and hatch hold S4-S5-S6 locations. Hence, the SLC must decide in which hold/deck locations of the bays assigned to A1 to load the containers. Note that the containers of each alliance member are grouped according to their type, size and weight. Capacity, operational, structural and stability constraints cannot be violated (see for example Ambrosino et al, 2017 for a description of such constraints). Other rules can also be applied in the definition of stowage plans; for instance, in a hatch location, either on deck or in the hold, only containers with the same destination can be stowed.

If partner A1 must stow one hazardous container, the SLC has to identify a slot for it among those in bays $22,26,30,54,58,62$. The stowage of the container must respect the international segregation rules described below. Figure $2 d$ depicts all the slots of bay 22 . Each slot is identified by its three coordinates, giving its position with respect to the three dimensions of the ship. The first coordinate is the bay, which gives to slot's position relative to the cross section of the ship (counted from fore to aft). The second coordinate is the row, which gives the slot's position relative to the vertical section of the corresponding bay (counted from the middle to outside). The third coordinate is the tier, which gives its position relative to the horizontal section of the corresponding bay (counted from the bottom to the top) (for more details, see Ambrosino et al, 2004).

Insert Figure 2 here

The objective of the SLC is to define a stowage plan so as to satisfy all the above mentioned constraints and to minimize ship time at berth for cargohandling operations. Thus, the SLC chooses the locations in a way as to avoid re-handles and balance the handling operations of cranes working in parallel. Note that the SLC knows in advance the assignment of quay cranes to ship bays at each port (see Ambrosino et al, 2017 for more details).

Here a new procedure for solving the MP-MBPP with dangerous goods is proposed. In particular, the segregation rules described below are integrated with the procedure presented in Ambrosino et al (2015). 


\section{Stowage and segregation rules by IMDG Code}

International regulations divided dangerous goods into nine hazard classes. These are presented in Table 1; class 9 is 'residual', i.e. it includes all dangerous substances not belonging to the other classes (e.g. elevated temperature liquids).

Hazard classes help to identify the risk connected to the substance, in order to take the necessary precautions, defined by law. Dangerous goods are listed in the IMDG Code, which classifies all materials and substances most commonly transported and considered relevant from a commercial point of view However, the code is not to be intended as complete, in fact needing constant updating. The list contains relevant information, such as hazard class, subsidiary risks, packing group (where assigned), packing and tank transport provisions, segregation and stowage, properties and observations. In stowage planning operations, particular attention should be paid to the segregation principles described in the IMDG Code (IMO, 2014). Among others, the code states that incompatible goods shall be segregated from one another. Two substances are considered incompatible when their close stowage may result in undue hazards in case of leakage or spillage, or any other accident. More, incompatible goods may react chemically in the case of an accident, causing serious, even lifethreatening, damage due to explosion, production of noxious or mortal gases, and so on. In these terms, the stowage of dangerous goods implies additional constraints in the MBPP (Ambrosino and Sciomachen, 2015).

\section{Insert Table 1 here}

The segregation rules are guidelines, which have to be followed, in order to assure safety of the whole cargo during the sea passage. The rules require (a) maintaining certain distance between incompatible goods; (b) requiring one or more steel bulkheads, or decks, between them; (c) a combination of (a) and (b).

When preparing the stowage plan, from the Document of Compliance, the SLC has to verify first the spaces on the ship allowed to accommodate dangerous goods. Then, he has to verify the stowage category of the goods inside the container, as indicated in the IMDG Code, which defines some stowing priority (IMO, 2014).

The Document of Compliance for the carriage of dangerous goods certifies whether, and where, such goods could be located on the ship. This is required by SOLAS and the document is unique for each ship. In it, the ship is divided into different parts and the document states which class of a dangerous good could be stowed in what part. Moreover, from the Dangerous Goods List in column 16.a, the SLC shall take note of the stowage category of each dangerous container to load (in the present work, only closed containers, whose stowage categories of IMDG Code are given in Table 2, are considered, even if the IMDG code distinghishes closed and opened containers).

Insert Table 2 here 
Most of the stowage categories could be stowed both on deck and in hold; three categories must be absolutely stowed on deck and three categories (11, 12 and 13) must always be located on deck or in special slots under deck. These limitations should be combined with the segregation rules, defined by the IMDG Code, verifying the classes of containers to load. The segregation table is reported in Table 3.

The SLC shall check compatibility between classes of two hazardous containers to stow, through Table 3 , defining the segregation rules. The compatibility rules are four, namely segregation rules 1, 2, 3 and 4, with the following meaning:

1. "Away from";

2. "Separated from";

3. "Separated by a complete compartment or hold from";

4. "Separated longitudinally by an intervening complete compartment or hold from".

Exceptions to these rules are pairs of containers of class 1 and the " $\mathrm{X}$ " cases, for which different rules are specified.

Insert Table 3 here

Figure 3 illustrates the rules in terms of the constraints that have to be observed in the case of stowage planning involving hazardous containers. Yellow slots are locations where dangerous containers are already stowed and red slots are locations around them where stowing additional dangerous containers is not allowed. Transparent slots are those where more dangerous containers can be stowed. Curved arrows mean that the corresponding two blocks are actually adjacent.

The first rule is the less restrictive one: in particular, in case of a pair of closed containers, no segregation rules shall be considered. The second rule (Figure 3a) says that incompatible containers cannot be stowed in the same vertical line, unless segregated by the deck. This means that incompatible containers cannot be in the same row and bay if both are located under deck (or on deck). However, incompatible containers can be in the same row and bay if one is in the hold and the other on deck (thanks to the hatch covers). In the horizontal line, fore and aft and athwart ships, at least one container slot is required, both on deck and under deck. This means that incompatible containers cannot be in successive bays (fore and aft) and in successive rows (athwart ships). However, if incompatible containers are under deck, in the same horizontal line, fore and aft, they can be separated by a bulkhead. The third rule (Figure 3b) distinguishes the stowage on the deck from that under deck: in the first case the rule is similar to the second one with the difference that in athwart ships incompatible containers have to be separated by two container spaces. Instead, under deck, one bulkhead is required, both fore and aft and athwart ships. This means that incompatible containers cannot be in the slots of the bays within the bulkheads. The last rule (Figure 3c) imposes that incompatible containers cannot be in the same vertical line. In practice, incompatible containers cannot be in the same row and bay, even if one is under deck and the other is on deck. The same holds for athwart ships; while a minimum distance of 24 meters is needed fore and aft, both on deck and under deck. Moreover, under deck a bulkhead is needed too. 


\section{The proposed procedure for defining stowage plans with hazardous containers}

So far, many papers have dealt with the stowage planning problem, proposing models and various solution approaches for a simplified version of the problem that does not include the hazardous containers. Our procedure is the first attempt to support the SLC in his multi-port stowage process including hazardous containers. The procedure must be repeated each time a new transport demand has to be evaluated. The procedure is sketched in Figure 4.

\section{Insert Figure 4 here}

More precisely, the SLC executes the following procedures:

1. Multi-port stowage procedure (MPSP): this procedure is known as the stowage plan definition. Here, the SLC determines the stowage plan, including the new transport demand, without hazardous containers (see Ambrosino et al, 2015);

2. Hazardous container procedure (HCP): this procedure is called for the stowage of hazardous containers. The SLC determines the exact slot for stowing hazardous containers, without violating the rules of the IMDG Code.

Before describing in more detail the above procedures, it could be of use to introduce the following notation (it is assumed that the SLC considers only bay locations (see Figure 2a)).

I $\quad$ set of all bays of the ship;

$I_{m} \quad$ subset of all bays assigned to alliance member $m$;

$C_{m} \quad$ set of containers of carrier $m$;

$C_{m_{d}} \quad$ subset of $m$ 's containers destined for port $d$;

$C_{m_{h}} \quad$ subset of hazardous containers of $m$;

$C_{m_{d}(h)} \quad$ subset of hazardous containers of $C_{m_{d}}$ destined to port $d$;

$I_{m_{C_{d}}} \quad$ subset of bays of $I_{m}$ devoted to the stowage of containers belonging to $C_{m_{d}}$;

$F_{m i} \quad$ set of free slots of $m$ in bay $i$.

\subsection{Multi-port stowage procedure (MPSP).}

When the SLC receives a new transport demand for a set of containers $C_{m}$ without hazardous ones from a partner $m$, he has to evaluate if accept it. With the MPSP procedure, he has the possibility to decide in which available locations to load the containers belonging to $C_{m} ; C_{m}$ is then split into different subsets according to their size $s$, type $t$, weight class $g$, and discharging port $d$. For each subset, the hold/deck hatch locations where it is possible to load it are determined.

Keeping in mind the structure of the ship and the way it is partitioned among the partners, the available locations are hence determined taking into account the cargo already on board or booked. The procedure can be easily adapted to different parts of the ship (i.e. Figures $2 a, 2 b$ and $2 c$ ). 
MPSP relies on the Mixed Integer Programming (MIP) heuristics of Ambrosino et al (2015), proposed for solving MP-MBPP. MPSP stows all containers in $C_{m}$ with the aim of minimizing re-handles and balanceing the handling operations of the quay cranes. In particular, the block stowage rule is used; that is, MPSP assigns only containers with the same destination in each deck/hold hatch location. The problem to be solved is relatively simple, since only few containers must be loaded, choosing among a limited number of available locations. Further, the capacity constraints are verified for all containers of each partner, loaded in the relative part of the ship. Finally, horizontal and the cross equilibrium stability conditions are verified (the reader can refer to Ambrosino et al, 2015, for more details about the procedure).

\subsection{Hazardous container procedure (HCP):}

When the SLC receives a new transport demand $C_{m}$ in which there are hazardous containers, he has to evaluate wheter to accept it or not. He can adopt the following procedure. Firstly, he has to determine the exact slots where to stow containers $C_{m_{h}}$; secondly, he has to decide where to stow the nonhazardous containers in $C_{m}$.

Procedure HCP is used to determine the slots for the hazardous containers. In particular, the incompatibilities given in the segregation table of the IMDG Code (see Table 3) are checked. When $C_{m_{h}}$ is assigned to the slots of partner $m$, the available locations for stowing the non-hazardous containers are updated and procedure MPSP is used.

The shipping company decides the best policy to follow when a new transport demand with hazardous containers has to be evaluated. When there is no free slot to stow a hazardous container, the SLC usually moves a standard container to make space. Also the SLC looks for a free slot only in the part of the ship assigned to $m$; this search is performed even if the block stowage is violated, also if a rehandle is necessary in order to move the container.

Procedure HCP is synthetized in Figure 5, where:

- the first block (BLOCK 1) concerns the assignment of hazardous containers of partner $m$, destined to port $d$, to free slots in the bays $I_{m_{C_{d}}}, d=1, \ldots, p$;

- the second path (BLOCK 2) asks to move normal containers, so as to allocate dangerous ones;

- the last path (BLOCK 3) moves to a different $I_{m_{g}}$, such that $g>d$, to allocate hazardous containers.

\section{Insert Figure 5 here}

The process starts by selecting a partner $m$ having hazardous containers to load. The first destination $d$ of this transport demand is selected next. Obviously, there could be destinations for which no hazardous container has to be loaded, i.e. $C_{m_{d(h)}}=\emptyset$; in this case, the next destination is considered. The first bay $i$ in $I_{m_{C_{d}}}$, such that $F_{m i}$ is not empty, is selected. Then, set $C_{m_{d(h)}}$ is sorted in increasing order according to the class of dangerous goods and the first container is chosen. For the chosen hazardous container the stowage slot is determined by following the steps performed in the previous phase, verifying the size, weight and segregation constraints. If all these constraints are satisfied, the 
stowage slot is confirmed, the set $F_{m i}$ is updated, and another container from $C_{m_{d(h)}}$, if present, is selected; otherwise, another free slot in $F_{m i}$ is selected. If no free slot is available in bay $i$, another bay of $I_{m_{C_{d}}}$ is selected and the process starts again (BLOCK 1 in Figure 5).

In the presence of a large number of containers, it may happen that no free slot can accommodate the selected dangerous container. In such a case, in the current bay, a standard container, already stowed, is taken from the top of its stack. Then, if all constraints are satisfied, the hazardous container is placed in that slot and the 'moved' standard container is stowed in a different location. In particular, if possible, the moved container is lowered in the same bay; otherwise, another bay in $I_{m}$ is selected, where containers with destination $g>d$ are located, verifying the size and weight constraints (BLOCK 2 in Figure 5).

When it is not possible to assign the hazardous container in a slot of $I_{m_{C_{d}}}$, the search continues by selecting a bay from $I_{m_{C_{g}}}$, such that $g>d$; the process is repeated as before to find a slot for the hazardous container (BLOCK 3 in Figure 5). If $I_{m_{C_{g}}}$, such that $g>d$, does not exist, the hazardous container cannot be accepted and loaded by the SLC (he might however accept it in another ship). In fact, it is not possible to load a dangerous container over a container with destination $j<d$, as they cannot be moved until their destination.

Finally, if it is not possible to find a slot for the moved container in $I_{m_{C}}$, due to its weight or size, the search starts in $F_{m i}$. In this case, procedure HCP verifies the slots in $I_{m_{C_{g}}}$, such that $g>d$, and, if necessary, searches for a slot in $I_{m_{C_{j}}}$, such that $j<d$ (see the last blocks). The process is repeated $\forall d=1, \ldots, p$ of partner $m$.

It is worth noting that the same situation arises in case of segregation rules 4 and 3 (under deck). In this case, the SLC must select another bay in $I_{m_{C_{g}}}$, with $g>d$, where there is a slot available for the hazardous container.

\section{Two simple examples of the suggested stowing policy}

To give an idea of how the proposed procedure would work, two simple, real-life, multi-port route examples, with hazardous containers to load, are now presented.

Consider a containership shared by two alliance members, namely $m 1$ and $m 2$, leaving the port of Genoa, in Italy, where some hazardous containers are loaded. The shipping demand of partner $m 1$ consists of 482 TEUs to load in Genoa for the following 3 destinations: Port Said Est, Singapore and Hong Kong. Table 4 reports, for each destination, the demand for 20' and 40' containers, both standard and hazardous. Containers are divided into three classes of weight $(10=$ light; $15=$ medium; $20=$ heavy). 
Hazardous containers are destined only to 2 destinations: Singapore, and Hong Kong. Thus, for Port Said Est, the procedure calls directly MPSP while, for Singapore and Hong Kong, HCP is also executed.

The classes of the hazardous containers are shown in Table 5.

Insert Table 4 here

Insert Table 5 here

Let us assume a cargo mix as the one depicted in Figure 6. The bays of partner $m 1$, assigned to stow containers destined to Port Said Est, Singapore and Hong Kong, respectively, are bays B54, B58 and B50.

Insert Figure 6 here

Procedure HCP searches the ship for a slot $l_{50 j k}$, where $j$ and $k$ are the row and tier coordinates of bay 50, to stow hazardous containers with destination Hong Kong. A similar search is performed in the slots of bay 58, for stowing hazardous containers destined to Singapore.

In this example, six dangerous containers, destined for Hong Kong (see their details in Table 6), and five for Singapore, must be stowed. Procedure HCP verifies the segregation rules along with the feasibility of the size and weight constraints. An example of the procedure, applied to partner $m 1$, is shown in Appendix 1.

\section{Insert Table 6 here}

The final stowage plan for partner $m 1$ is presented in Figure 7. In particular, the slot allocation in bays 54, 58 and 50, for stowing containers destined to Port Said Est, Singapore and Hong Kong respectively, is reported. Hazardous containers, depicted in red, are stowed only in bays 58 and 50.

\section{Insert Figure 7 here}

In particular, bay 58 accommodates 4 hazardous containers with destination Singapore: 3 TEUs (c382, c37 and c125) and 1 FEU (c458). Note that the 4 containers are compatible and are stowed close to each other. However, note that container $\mathrm{c} 125$ belongs to class 2.1 and hence it is not compatible with the other containers of class 3; for this reason, they need to be separated by the deck. Deck slots are also required for stowing all the hazardous containers destined for Hong Kong.

The case is easily solved by HCP due to the low occupation of these bays. Let us consider a second example in which we assume a different cargo situation, as the one depicted in Figure 8a for a generic bay. The bay under investigation has a capacity of 252 FEU and has a residual capacity of 53 FEU, having already stowed both 20' and 40' containers. In particular, the 52 20'containers already stowed are in dedicated stacks, while the others are under 40' containers (note that the opposite is not possible 
for the structural containers constraints). The SLC receives a demand for 2 hazardous $40^{\prime}$ containers and 32 standard 40' containers. By applying MSPS (see Figure 4), the SLC decides to accept the new transport demand and updates the plan, as seen in Figure $8 \mathrm{~b}$. Note that, the slots occupied by the 32 40 ' containers are those without a number, while the hazardous containers are in the red slots. After that, only 18 FEU slots are available.

\section{Insert Figure 8 here}

Suppose that the SCL has to load another 40' hazardous container, which requires segregation principle 3 . The 18 FEU slots available in the bay under consideration are forbidden for hazardous containers requiring segregation principle 3 . Since there is no available slot in this bay, the procedure moves an already stowed standard container, for instance from slot 09 , tier 94 . The "moved" container will be successively put in slot 04, tier 94. The final updated plan is reported in Figure 9.

In this case, in the current bay of partner $m l$, there was a slot available to receive the moved container. In the opposite, procedure HCP would have to search in another bay of the same partner. Then, the HCP would follow this order: 1) bay with the same destination $d$;2) bay with a destination $g>d ; 3$ ) bay with a destination $j<d$. Note that this search is guided by the procedure defined by the shipping company. In fact, the shipping company may use different strategies, thus different procedures. For example, if the SLC does not allow the movement of a standard container, the search will continue in another bay of the same partner following this order: 1) bay with the same destination $d$; 2) bay with a destination $g>d$.

Insert here Figure 9

\section{Conclusions}

Our paper has addressed the stowage-planning problem in the presence of dangerous containers, requiring additional constraints for their stowage onboard a containership. The sharing of ship capacity among alliance members has also been considered in the proposed stowage-planning.

We aim to assist the SLC in planning the stowage of hazardous containers, taking into account the segregation rules between incompatible classes of hazard, as well as the policy followed by the shipping company.

Our proposed procedure reflects the policies used by a certain liner company we are involved with. A company can hence adopt a block stowage and decide to ask for the cooperation among partners when particular stowage conditions are required.

Our procedure finds stowage solutions for ships with different structures, capacity and available sections for hazardous containers, and for companies having different stowage strategies. It is possible to implement our procedure in a tool able to verify the stowage constraints and the segregation rules in case of hazardous cargo. 
Finally, the proposed procedure can be applied even when the agreements between partners provide different limitations and arrangements with regard to sharing ship space.

\section{References}

1. Ambrosino D., Sciomachen A., Tanfani E. (2004). Stowing a containership: the master bay plan problem, Transportation Research Part A, pp.81-99.

2. Ambrosino D., Anghinolfi D., Paolucci M., Sciomachen A. (2009). A new three-step heuristic for the Master Bay Plan Problem, Maritime Economics \& Logistics, pp.98-120.

3. Ambrosino D., Paolucci M., Sciomachen A. (2015). Experimental evaluation of mixed integer programming models for the multi-port master bay plan problem, Flexible Service \& Manufacturing Journal, Vol. 27, pp. 263-284.

4. Ambrosino D., Sciomachen A. (2015). Using a Bin Packing Approach for Stowing Hazardous Containers into Containerships. In Optimized Packings with Applications, G. Fasano and J. D. Pintér Eds, pp. 1-17, Springer.

5. Ambrosino D., Paolucci M., Sciomachen A. (2017). Computational evaluation of a MIP model for a multi-port stowage planning problem, Soft Computing, Vol. 21, Issue 7, pp. 1753-1763.

6. Avriel, M., Penn, M. and Shpirer N. (2000). Container ship stowage problem: complexity and connection to the colouring of circle graphs, Discrete Applied Mathematics, 103, pp. 271-279.

7. Carlo H.J., Vis I.F.A., Roodbergen K.J. (2013) Storage yard operations in container terminals: Literature overview, trends, and research directions, European Journal of Operational Research, v. 235 , pp.412-430.

8. D’Arcy J. Ryan. (2001). Strategic Alliances and Their Impacts On the Container Shipping Industry.

9. Ding D., Chou M.C. (2015). Stowage planning for container ships: a heuristic algorithm to reduce the number of shifts, European Journal of Operational Research, pp.242-249.

10. Komini. (2014). The rise and dominance of Shipping Alliances in the Liner industry, Cardiff Business School, pp.1-18.

11. Imai, A., Sasaki, K., Nishimura, E., Papadimitriou, S. (2006). Multi-objective simultaneous stowage and load planning for a container ship with container rehandles in yard stacks, European Journal of Operational Research, v. 171, pp. 373-389.

12. Imai, A., Nishimura, E., Papadimitriou, S., (2013). Marine container terminal configurations for efficient handling of mega-containerships. Transportation Research Part E, 49 (1), 141-158.

13. IMO, International Convention for Safe Containers (CSC), 1972.

14. IMO, International Convention for the Safety of Life at Sea (SOLAS), 1974, Chapter VII, Chapter II-2.

15. IMO, International Convention for the Prevention of Pollution from Ships, (MARPOL 73/78), adopted in 1973, modified by Protocol 1978.

16. IMO, International Maritime Dangerous Goods (IMDG) Code. (2014). Edition incorporating Amendment 37-14.

17. Monaco M.F., Sammarra M., Sorrentino G. (2014). The terminal-oriented ship stowage planning problem, European Journal of Operational Research v.239, pp.256-265. 
18. Pacino D., Delgado A., Jensen R.M., Bebbington T. (2011). Fast generation of near-optimal plans for eco- efficient stowage of large container vessels. In Bse J., Hu H., Jahn C., ShiX., Stahlbock R., Voss S. (eds), Computational logistics. Lecture notes in computer science, pp. 286-301.

19. Parreno, F., Pacino, D. , Alvarez-Valdes, R. (2016). A GRASP algorithm for the container stowage slot planning problem, Transportation Research. Part E: Logistics and Transportation Review, 94, pp.141-157.

20. Rashidi H., Tsang E. (2013). Novel constraints satisfaction models for optimization problems in container terminals, Applied Mathematical Model, 37, 3601-3634.

21. Shi X., Meersman H., Voss S. (2008). The win-win game in slot-chartering agreement among the liner competitors and collaborators, International Association of Maritime Economists.

22. Stahlbock, R., Voss, S. (2008). Operations research at container terminal: a literature update, $O R$ Spectrum 30, pp. 1-52.

23. Steenken, D., Voß, S., \& Stahlbock, R. (2004). Container terminal operation and operations research - A classification and literature review, OR Spectrum, 26(1), pp. 3-49.

24. Tierney, K., Pacino, D., Møller, J. R. (2014). On the complexity of container stowage planning problems, Discrete applied mathematics, v.169, pp.225-230.

25. Wilson, D., Roach, P.A. (2000). Container stowage planning: a methodology for generating computerised solutions. J Oper Res Soc 51(11), pp. 1248-1255.

26. Wilson, D., Roach, P.A., Ware, J.A. (2001). Container stowage pre-planning: using search to generate solutions, a case study, Knowl-Based Syst, 14(3-4), pp.137-145.

\section{Acknowledgment}

The authors wish to thank the reviewers for their work and their comments and suggestions that permit to improve the manuscript. Special Thanks to the Editor Hercules Haralambides for his precious additional suggestions.

\section{Appendix 1.}

An example of the proposed HCP procedure applied to partner $m 1$ for stowing container with destination Singapore is as follows:

$\gg$ Destination $2^{\text {th }}:$ Singapore.

- $C_{m 1 d 2(h)} \neq \varnothing$.

- Among $I_{m 1} C_{d 2},\{B 57, B 58, B 59\}$ is selected.

- $\quad c 382 \rightarrow 20$, class $3, w_{c 382}=10$. B57 is selected.

- Assign c382 to $l_{B 57, R 14, T 84}$.

- Verify the constraints:

1. size: $l_{B 57, R 14, T 82}$ assigned to $c 562 \rightarrow 20^{\prime} \rightarrow O K$.

2. weight: $w_{c 562}=10, w_{c 382}=w_{c 562} \rightarrow O K$.

3. segregation: "Stowage Category $B$ " $\rightarrow$ on deck/under deck $\rightarrow O K$.

- $\quad$ The assignment is confirmed.

- Update:

$$
\begin{aligned}
& F_{m 1, B 57}=F_{m 1, B 57} \backslash\left\{l_{B 57, R 14, T 84}\right\} ; \\
& F=F_{m 1, B 58} \backslash\left\{l_{B 58, R 14, T 84}\right\}
\end{aligned}
$$

- $C_{m 1 d 2(h)} \neq \varnothing$.

- Among $I_{m 1 C_{d 2}},\{B 57, B 58, B 59\}$ is selected.

- $\quad c 37 \rightarrow 20^{\prime}$, class $3, w_{c 37}=10$. B57 is selected.

- Assign c37 to $l_{B 57, R 14, T 86 \text {. }}$

- Verify the constraints: 
1. size: $l_{B 57, R 14, T 84}$ assigned to $c 382 \rightarrow 20^{\prime} \rightarrow O K$.

2. weight: $w_{c 382}=10, w_{c 37}=w_{c 382} \rightarrow O K$.

3. segregation:

* "Stowage Category B" $\rightarrow$ on deck/under deck $\rightarrow$ OK.

* $l_{B 57, R 14, T 84}$ assigned to c382 $\rightarrow$ segregation rule " $X$ " $\rightarrow O K$.

- $\quad$ The assignment is confirmed.

- Update:

$$
\begin{aligned}
& F_{m 1, B 57}=F_{m 1, B 57} \backslash\left\{l_{B 57, R 14, T 86}\right\} ; \\
& F_{m 1, B 58}=F_{m 1, B 58} \backslash\left\{l_{B 58, R 14, T 86}\right\} ;
\end{aligned}
$$

- $C_{m 1 d 2(h)} \neq \emptyset$.

- Among $I_{m 1} C_{d 2},\{B 57, B 58, B 59\}$ is selected.

- $\quad c 41 \rightarrow 20^{\prime}$, class $8, w_{c 41}=10$. B57 is selected.

- Assign c41 to $l_{B 57, R 14, T 88}$.

- Verify the constraints:

1. size: $l_{B 57, R 14, T 86}$ assigned to $c 37 \rightarrow 20^{\prime} \rightarrow O K$.

2. weight: $w_{c 37}=10, w_{c 41}=w_{c 37} \rightarrow O K$.

3. segregation:

* "Stowage Category C" $\rightarrow$ on deck only $\rightarrow$ OK.

* $\quad l_{B 57, R 14, T 86}$ assigned to $c 37 \rightarrow$ segregation rule " $X$ " $\rightarrow O K$.

- $\quad$ The assignment is confirmed.

- Update:

$$
\begin{aligned}
& F_{m 1, B 57}=F_{m 1, B 57} \backslash\left\{l_{B 57, R 14, T 88}\right\} ; \\
& F_{m 1, B 58}=F_{m 1, B 58} \backslash\left\{l_{B 58, R 14, T 88}\right\} ;
\end{aligned}
$$

- $C_{m 1 d 2(h)} \neq \varnothing$.

- Among $I_{m 1 C_{d 2}},\{B 57, B 58, B 59\}$ is selected.

- $\quad c 458 \rightarrow 40$, class $8, w_{c 458}=15$. B58 is selected.

- Assign c458 to $l_{B 58, R 14, T 90}$.

- Verify the constraints:

1. size: $l_{B 58, R 14, T 88}$ assigned to $c 41 \rightarrow 20^{\prime} \rightarrow O K$.

2. weight: $w_{C 41}=10, w_{c 458}>w_{C 41} \rightarrow N O$.

- Assign c458 to $l_{B 58, R 12, T 90}$.

- Verify the constraints:

1. size: $l_{B 58, R 12, T 88}$ assigned to $c 568 \rightarrow 40^{\prime} \rightarrow O K$.

2. weight: $w_{c 568}=15, w_{c 458}<w_{c 568} \rightarrow O K$.

3. segregation:

* "Stowage Category A" $\rightarrow$ on deck/under deck $\rightarrow O K$.

* $\quad l_{B 57, R 14, T 86}$ assigned to $337 \rightarrow$ segregation rule " $X$ " $\rightarrow O K$.

* $\quad l_{B 57, R 14, T 84}$ assigned to $c 382 \rightarrow$ segregation rule " $X$ " $\rightarrow O K$.

* $\quad l_{B 57, R 14, T 88}$ assigned to $c 41 \rightarrow$ segregation rule " $X$ " $\rightarrow O K$.

- $\quad$ The assignment is confirmed.

- Update:

$$
\begin{gathered}
F_{m 1, B 57}=F_{m 1, B 57} \backslash\left\{l_{B 57, R 12, T 88}\right\} ; \\
F_{m 1, B 58}=F_{m 1, B 58} \backslash\left\{l_{B 58, R 12, T 88}\right\} ; \\
F_{m 1, B 59}=F_{m 1, B 59} \backslash\left\{l_{B 59, R 12, T 88}\right\} ;
\end{gathered}
$$

- $\quad C_{m 1 d 2(h)}=\varnothing$.

(the process continues until destination 3=Hong Kong). 


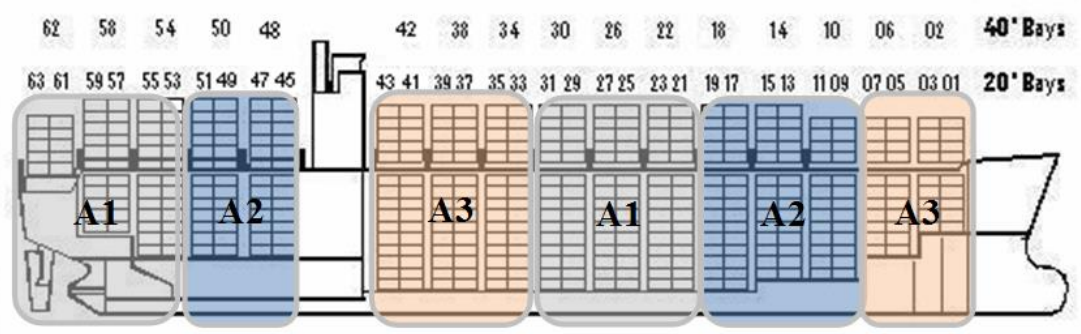

Figure 1. Ship partitioning among alliance members

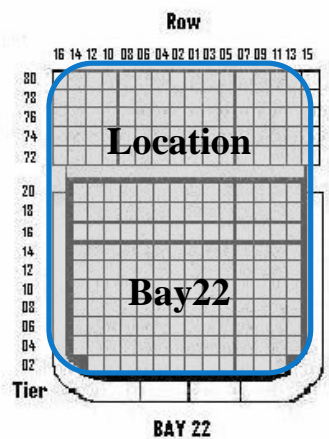

(a)

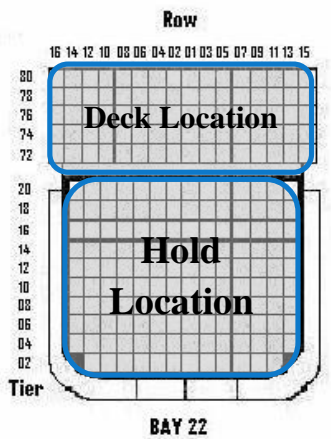

(b)

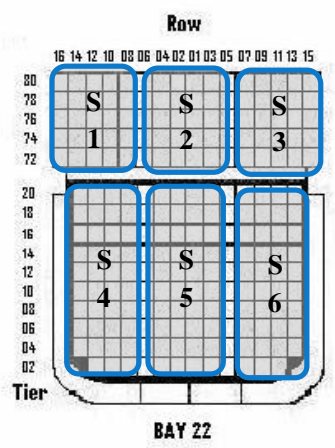

(c)

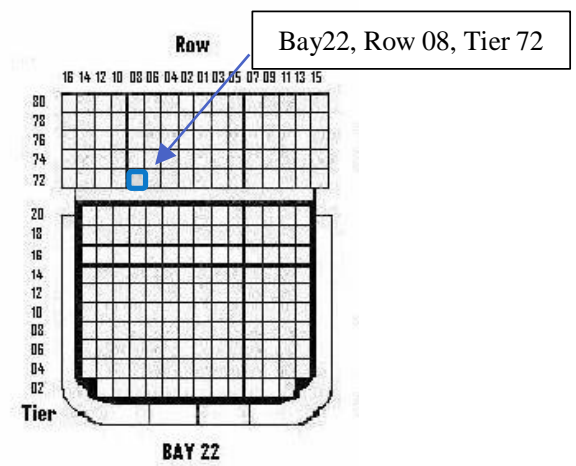

(d)

Figure 2. Locations of a bay 

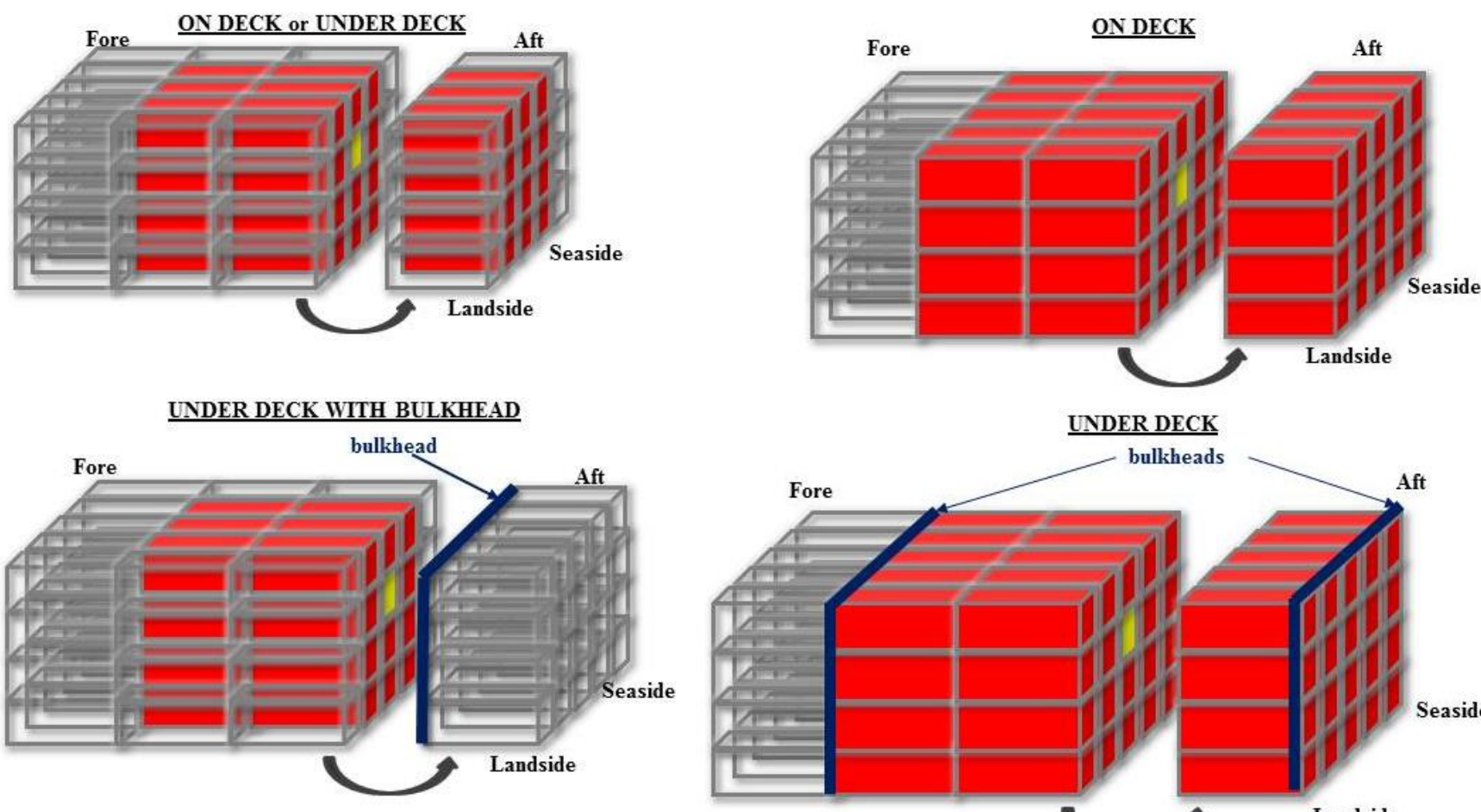

a.

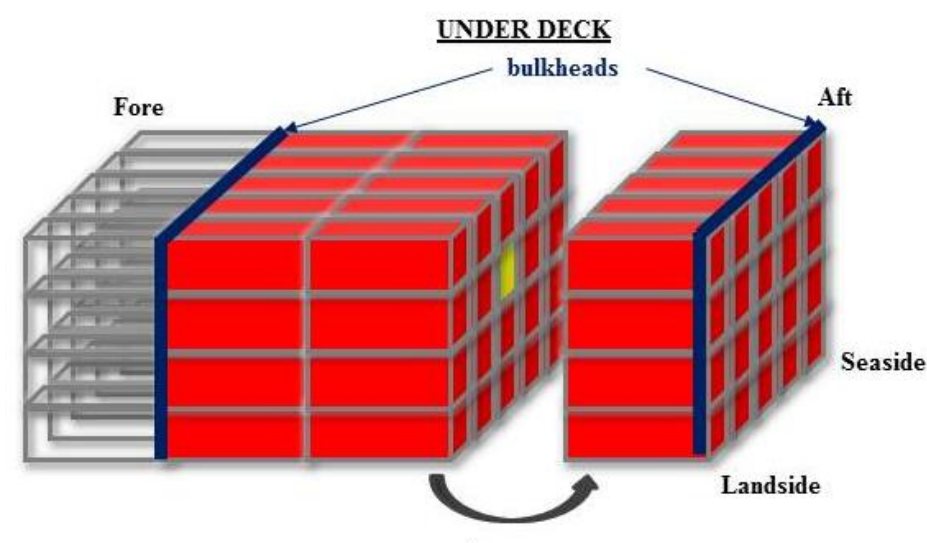

b.

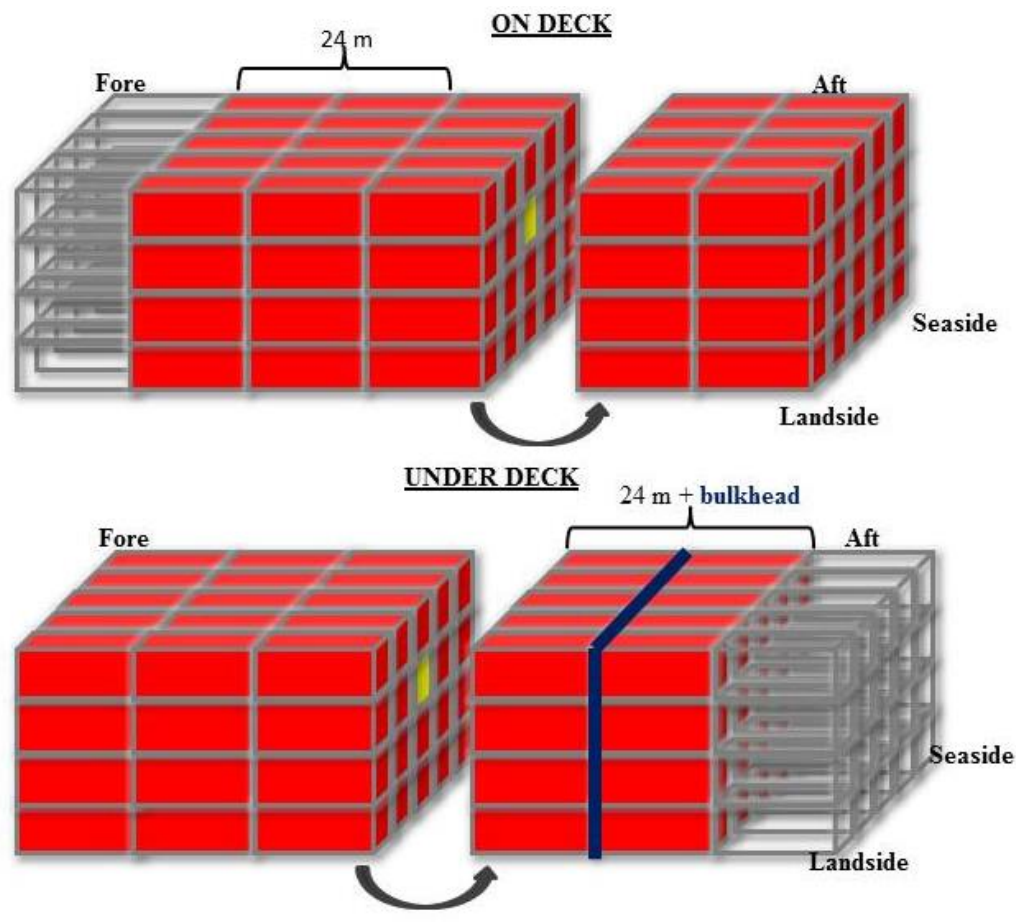

c. 
Figure 3. a: $2^{\text {nd }}$ segregation rule. b: $3^{\text {rd }}$ segregation rule. c: $4^{\text {th }}$ segregation rule.

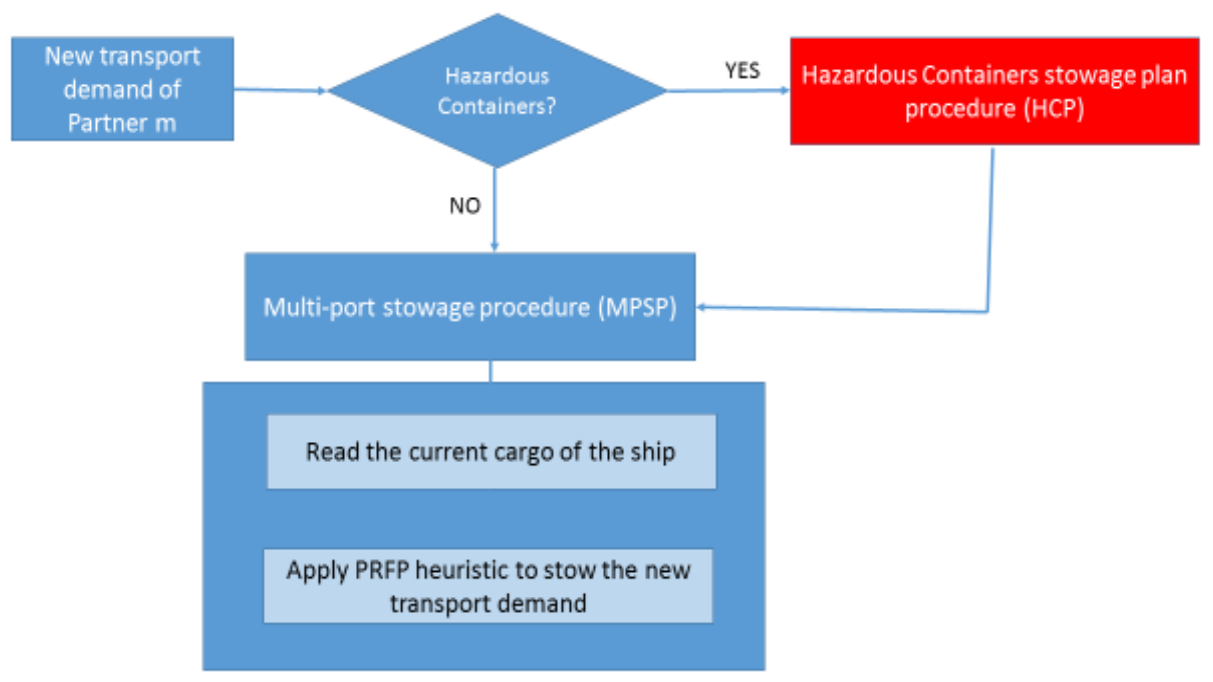

Figure 4: general stowing procedure with hazardous goods 


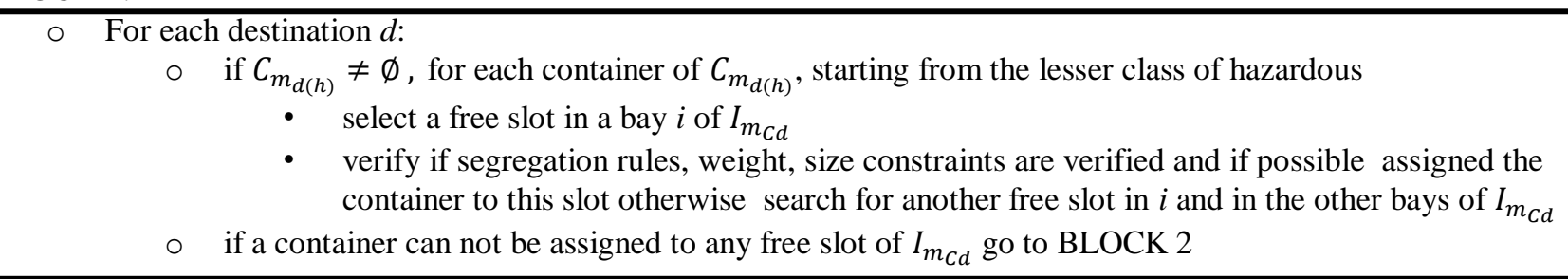

\section{BLOCK 2:}

$\circ$ For the container with destination $d$ :

- Search among the occupied slots of $I_{m_{C d}}$ a slot able to receive the hazardous container

- If this slot exits:

- move the standard container from this slot

- assign the hazardous container to this slot

○ search a slot for the «moved» container among the free slots of $I_{m_{C d}}$ : if this slot does not exist go to BLOCK 3

○ Otherwise go to BLOCK 3

\section{BLOCK 3:}

For the container with destination $d$ :

$\circ$ if it is a «moved» container:

$\circ \quad$ For each set $I_{m_{C g}}$ such that $g>d$

- $\quad$ select a free slot in a bay $i$ of $I_{m_{C g}}$

- Verify weight, size constraints and if possible assigned the container to this slot otherwise search for another free slot in $i$ and in the other bays of $I_{m_{C g}}$

- If the container can not be assigned to any free slot of $I_{m_{C g}} \forall g>d$, search for a free slot in $I_{m_{C j}}$ such that $j<d$

- If the container can not be assigned to any free slot of $I_{m_{C j}} \forall j<d$ STOP: «It is not possible to accept the hazardous container causing this movement»

- Otherwise assign the container to this slot

$\circ$ Otherwise (it is a hazardous container)

- Otherwise assign the container to this slot

- For each set $I_{m_{C g}}$ such that $g>d$

- $\quad$ select a free slot in a bay $i$ of $I_{m_{C g}}$

- Verify segregation rules, weight, size constraints and if possible assigned the container to this slot otherwise search for another free slot in $i$ and in the other bays of $I_{m_{C g}}$

- If the container can not be assigned to any free slot of $I_{m_{C g}} \forall g>d$ STOP: «It is not possible to accept this container»

Figure 5. The Hazardous Containers stowage plan procedure (HCP)

\begin{tabular}{|c|c|c|c|c|c|}
\hline \multicolumn{2}{|c|}{ B58 } & \multicolumn{2}{|c|}{ B54 } & \multicolumn{2}{|c|}{ B50 } \\
\hline B59 & B57 & B55 & B53 & B51 & B49 \\
\hline $\mathrm{Cm}$ & SIN & $\mathrm{Cml}$ & 1 PSE & $\mathrm{Cml}, \mathrm{C}$ & HKG \\
\hline
\end{tabular}


Figure 6: bays of partner $m 1$ and their related cargo.

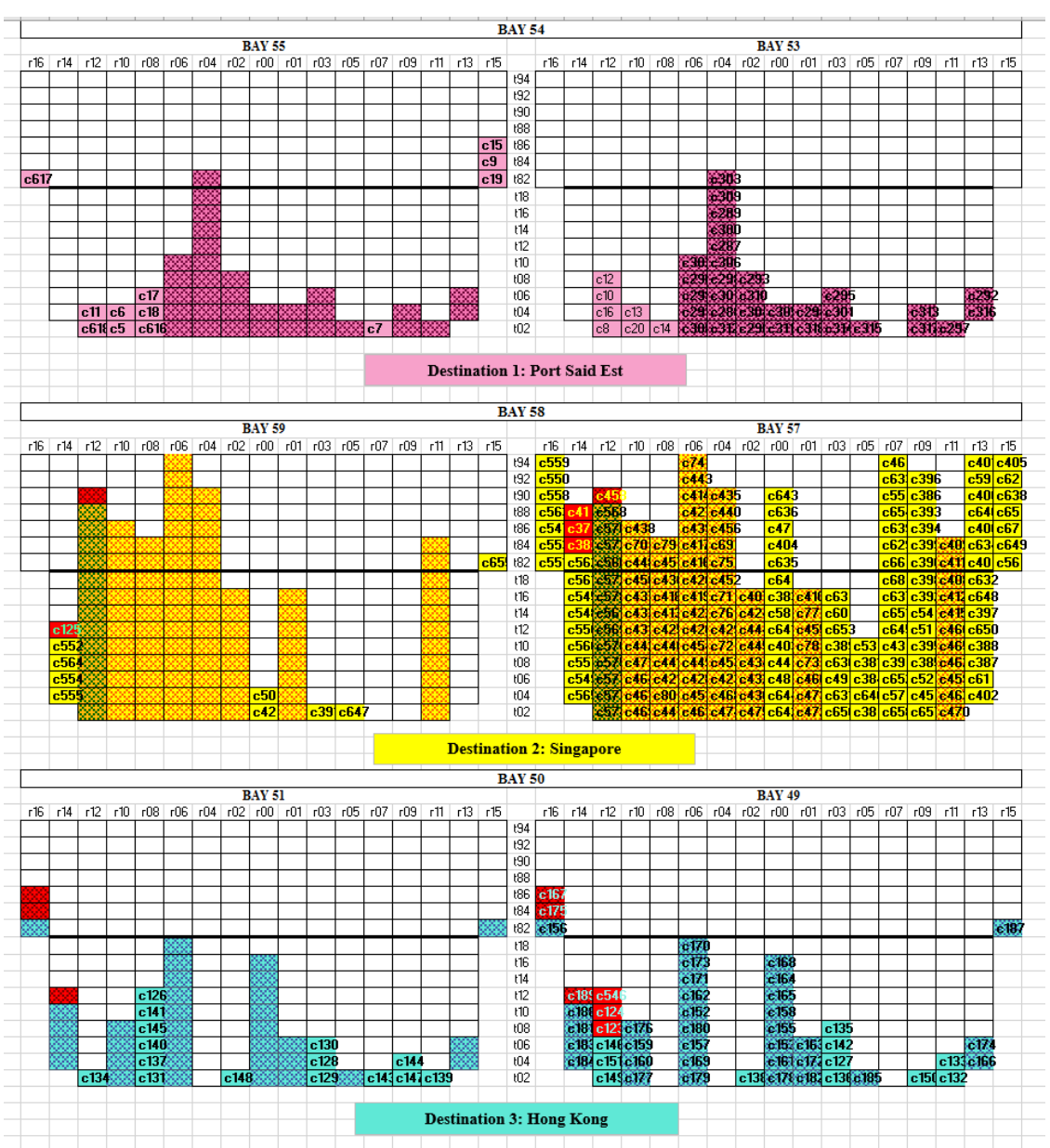

Figure 7: Final stowage plan for partner $m 1$ involving bays 50, 54 and 58. 


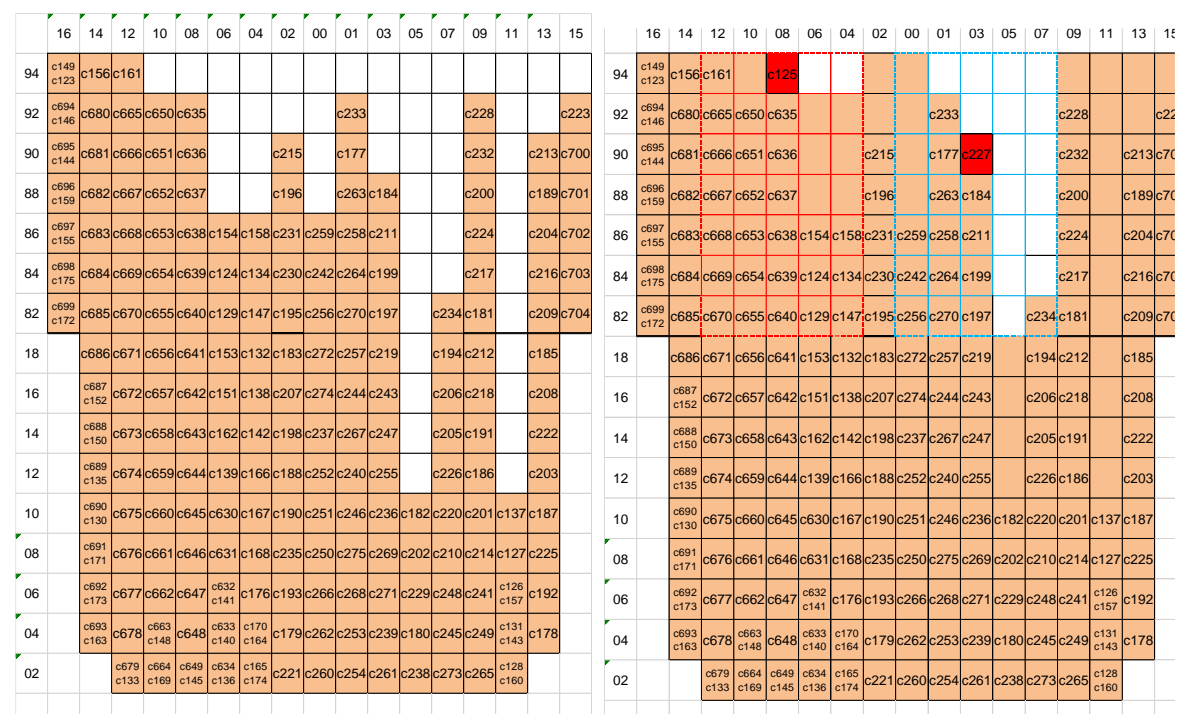

Figure 8: a) the already stowed containers $\quad$; b) the stowage plan for a bay with destination $d$ of partner $m 1$.

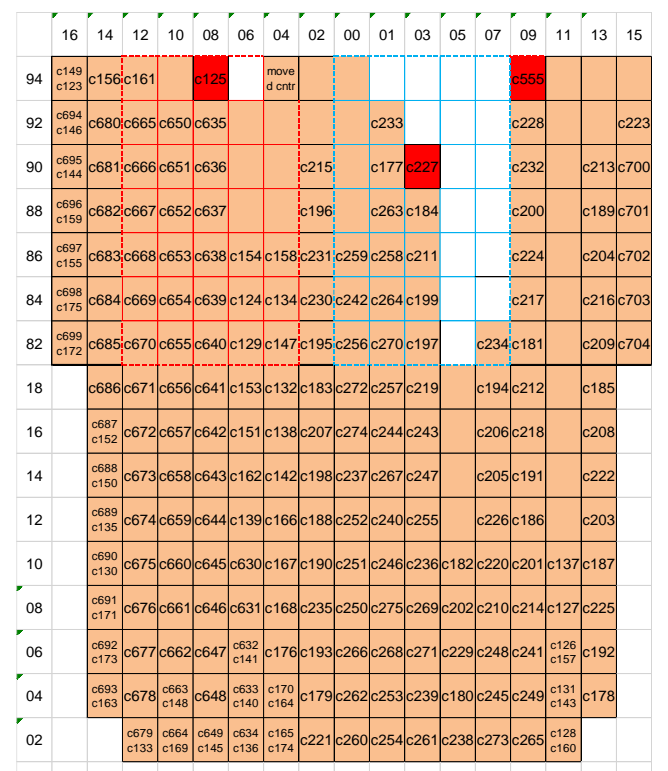

Figure 9: stowage plan for the bay with destination $d$ of partner $m 1$. 
Table 1. Classification of dangerous goods by IMDG Code, Part 2, and Marking and labelling of packages by IMDG Code, Chapter 5.2.

\begin{tabular}{|c|c|}
\hline Class & Name \\
\hline 1 & Explosives \\
\hline 2 & Gases \\
\hline 3 & Flammable Liquids \\
\hline 4 & Flammable Solids or Substances \\
\hline 5 & Oxidizing Substances and Organic Peroxides \\
\hline 6 & Toxic and Infectious Substances \\
\hline 7 & Radioactive Substances \\
\hline 8 & Corrosive Substances \\
\hline 9 & Miscellaneous Dangerous Substances and Articles \\
\hline
\end{tabular}

Table 2. Stowing categories for closed containers, from IMDG Code (IMO, 2014).

\begin{tabular}{|c|l|}
\hline & Cargo containerships \\
\hline $\begin{array}{c}\text { Stowage category A, B, E } \\
\text { Stowage category 01, 02, 03, 04, 05, 06, 07, 08, 09, 10, 15 }\end{array}$ & On deck or under deck \\
\hline $\begin{array}{c}\text { Stowage category C, D } \\
\text { Stowage category 14 }\end{array}$ & On deck only \\
\hline Stowage category 11, 12 & $\begin{array}{l}\text { On deck in closed containers or under deck } \\
\text { in slot stowage type "c" }\end{array}$ \\
\hline Stowage category 13 & $\begin{array}{l}\text { On deck on closed containers or under deck } \\
\text { in a slot stowage type "a" }\end{array}$ \\
\hline
\end{tabular}

Table 3. Segregation table of IMDG Code.

\begin{tabular}{|c|c|c|c|c|c|c|c|c|c|c|c|c|c|c|c|c|c|}
\hline CLASS & $\begin{array}{l}1.1 \\
1.2 \\
1.5\end{array}$ & $\begin{array}{l}1.3 \\
1.6\end{array}$ & 1.4 & 2.1 & 2.2 & 2.3 & 3 & 4.1 & 4.2 & 4.3 & 5.1 & 5.2 & 6.1 & 6.2 & 7 & 8 & 9 \\
\hline $1.1,1.2,1.5$ & $\cdot$ & $\cdot$ & $\cdot$ & 4 & 2 & 2 & 4 & 4 & 4 & 4 & 4 & 4 & 2 & 4 & 2 & 4 & $\mathrm{x}$ \\
\hline Explosives & $\cdot$ & $\cdot$ & $\cdot$ & 4 & 2 & 2 & 4 & 3 & 3 & 4 & 4 & 4 & 2 & 4 & 2 & 2 & $x$ \\
\hline Explosives & $\cdot$ & $\cdot$ & $\cdot$ & 2 & 1 & 1 & 2 & 2 & 2 & 2 & 2 & 2 & $x$ & 4 & 2 & 2 & $\mathrm{x}$ \\
\hline Flammable gases & 4 & 4 & 2 & $x$ & $\mathrm{x}$ & $x$ & 2 & 1 & 2 & $\mathrm{x}$ & 2 & 2 & $x$ & 4 & 2 & 1 & $x$ \\
\hline Non-toxic, non-flammable gases & 2 & 2 & 1 & $x$ & $\mathrm{x}$ & $\mathrm{x}$ & 1 & $\mathrm{x}$ & 1 & $\mathrm{x}$ & $\mathrm{x}$ & 1 & $\mathrm{x}$ & 2 & 1 & $\mathbf{x}$ & $x$ \\
\hline Toxic gases & 2 & 2 & 1 & $\mathbf{x}$ & $\mathbf{x}$ & $\mathrm{x}$ & 2 & $\mathrm{x}$ & 2 & $\mathrm{x}$ & $\mathrm{x}$ & 2 & $x$ & 2 & 1 & $\mathrm{x}$ & $x$ \\
\hline Flammable liquids & 4 & 4 & 2 & 2 & 1 & 2 & $x$ & $x$ & 2 & 1 & 2 & 2 & $x$ & 3 & 2 & $x$ & $x$ \\
\hline $\begin{array}{l}\text { Flammable solids (including sell- } \quad 4.1 \\
\text { reactive substances and solid } \\
\text { desensitized explosives) }\end{array}$ & 4 & 3 & 2 & 1 & $x$ & $\mathrm{x}$ & $x$ & $x$ & 1 & $\mathrm{x}$ & 1 & 2 & $\mathrm{x}$ & 3 & 2 & 1 & $\mathrm{x}$ \\
\hline $\begin{array}{l}\text { Substances liable to } \\
\text { spontaneous combustion }\end{array}$ & 4 & 3 & 2 & 2 & 1 & 2 & 2 & 1 & $\mathrm{x}$ & 1 & 2 & 2 & 1 & 3 & 2 & 1 & $x$ \\
\hline $\begin{array}{l}\text { Substances which, in contact } \\
\text { with water, emit flammable gases }\end{array}$ & 4 & 4 & 2 & $\mathrm{x}$ & $\mathrm{x}$ & $\mathrm{x}$ & 1 & $\mathrm{x}$ & 1 & $\mathrm{x}$ & 2 & 2 & $x$ & 2 & 2 & 1 & $\mathrm{x}$ \\
\hline Oxidlzing substances (agents) & 4 & 4 & 2 & 2 & $x$ & $x$ & 2 & 1 & 2 & 2 & $x$ & 2 & 1 & 3 & 1 & 2 & $\mathrm{x}$ \\
\hline Organic peroxides & 4 & 4 & 2 & 2 & 1 & 2 & 2 & 2 & 2 & 2 & 2 & $\mathrm{x}$ & 1 & 3 & 2 & 2 & $x$ \\
\hline Toxic substances & 2 & 2 & $x$ & $x$ & $x$ & $x$ & $x$ & $\mathrm{x}$ & 1 & $\mathrm{x}$ & 1 & 1 & $x$ & 1 & $\mathrm{x}$ & $\mathrm{x}$ & $\mathrm{x}$ \\
\hline Infectious substances & 4 & 4 & 4 & 4 & 2 & 2 & 3 & 3 & 3 & 2 & 3 & 3 & 1 & $\mathrm{x}$ & 3 & 3 & $\mathrm{x}$ \\
\hline Radioactive material & 2 & 2 & 2 & 2 & 1 & 1 & 2 & 2 & 2 & 2 & 1 & 2 & $x$ & 3 & $\mathrm{x}$ & 2 & $x$ \\
\hline Corrosive substances & 4 & 2 & 2 & 1 & $x$ & $x$ & $x$ & 1 & 1 & 1 & 2 & 2 & $x$ & 3 & 2 & $x$ & $x$ \\
\hline $\begin{array}{l}\text { Miscellaneous dangerous } \\
\text { substances and articles }\end{array}$ & $x$ & $x$ & $x$ & $x$ & $x$ & $x$ & $x$ & $x$ & $x$ & $x$ & $x$ & $x$ & $x$ & $x$ & $x$ & $x$ & $x$ \\
\hline
\end{tabular}


Table 4: Shipping demand from Genoa.

\begin{tabular}{|c|l|c|c|c|c|}
\hline Partner & Destination & $\mathbf{2 0}^{\prime}$ & $\mathbf{4 0}^{\prime}$ & haz 20' & haz 40' \\
\hline \multirow{4}{*}{$\boldsymbol{\Xi}$} & 1. PSE & 19 & 32 & - & - \\
\cline { 2 - 6 } & 2. SIN & 85 & 79 & 4 & 1 \\
\cline { 2 - 6 } & $3 . \mathrm{HKG}$ & 46 & 48 & 3 & 3 \\
\cline { 2 - 6 } & TEUs & 150 & 318 & 6 & 8 \\
\hline
\end{tabular}

Table 5: Hazardous containers.

\begin{tabular}{|c|l|c|c|c|c|}
\hline \multirow{2}{*}{ Partner } & Destination & haz 20' & Class & haz 40' & Class \\
\hline \multirow{2}{*}{$\mathrm{m} 1$} & $2 . \mathrm{SIN}$ & 4 & $\mathrm{Cl} .3, \mathrm{Cl} .3, \mathrm{Cl} .8, \mathrm{Cl} .2 .1$ & 1 & $\mathrm{Cl} .8$ \\
\cline { 2 - 6 } & $3 . \mathrm{HKG}$ & 3 & $\mathrm{Cl} .3, \mathrm{Cl} .3, \mathrm{Cl} .3$ & 3 & $\mathrm{Cl} .2 .2, \mathrm{Cl} .3, \mathrm{Cl} .8$ \\
\hline
\end{tabular}

Table 6: Dangerous Goods List of containers already on board

\begin{tabular}{|c|c|c|c|c|c|}
\hline & \multicolumn{5}{|c|}{ 2. Singapore } \\
\hline $\mathbf{C}$ & Size & UN no. & Proper Shipping Name & Class & Stowing Category \\
\hline c382 & $20^{\prime}$ & 1987 & Alcohols N.O.S & 3 & $\mathrm{~B}$ \\
\hline c37 & $20^{\prime}$ & 1987 & Alcohols N.O.S & 3 & $\mathrm{~B}$ \\
\hline $\mathrm{c} 41$ & $20^{\prime}$ & 2218 & Acrylic Acid, Stabilized & 8 & $\begin{array}{l}\text { C Shade from radiant } \\
\text { heat. Clear of leaving } \\
\text { quarters. }\end{array}$ \\
\hline $\mathrm{c} 458$ & $40^{\prime}$ & 2506 & Ammonium Hydrogen Sulphate & 8 & $\begin{array}{l}\text { A Clear of leaving } \\
\text { quarters. }\end{array}$ \\
\hline \multirow[t]{2}{*}{$\mathrm{c} 125$} & $20^{\prime}$ & 1075 & Petroleum Gases, Liquefied & 2.1 & $\begin{array}{l}\text { E Clear of leaving } \\
\text { quarters. }\end{array}$ \\
\hline & \multicolumn{5}{|c|}{ 3. Hong Kong } \\
\hline $\mathbf{C}$ & Size & UN no. & Proper Shipping Name & Class & Stowing Category \\
\hline c546 & $20^{\prime}$ & 1136 & Coal Tar Distillates, Flammable & 3 & $\mathrm{~B}$ \\
\hline $\mathrm{c} 123$ & $20^{\prime}$ & 2057 & Tripropylene & 3 & A \\
\hline c124 & $20^{\prime}$ & 2057 & Tripropylene & 3 & $\mathrm{~A}$ \\
\hline $\mathrm{c} 175$ & $40^{\prime}$ & 1968 & Insecticide Gas, N.O.S. & 2.2 & A \\
\hline c167 & $40^{\prime}$ & 1114 & Benzene & 3 & $\begin{array}{l}\text { B Clear of leaving } \\
\text { quarters. }\end{array}$ \\
\hline c189 & $40^{\prime}$ & 2506 & Ammonium Hydrogen Sulphate & 8 & $\begin{array}{l}\text { A Clear of leaving } \\
\text { quarters. }\end{array}$ \\
\hline
\end{tabular}

